\title{
Investigation on Mental Health of Primary and Middle School Teachers
}

\author{
Li Chaojun
}

\author{
No. 249 Huanghe Road Puyang Vocationa and Technical College, Puyang,Henan, China \\ pylchj@126.com
}

Keywords: Teachers in primary and middle schools; Psychological health; Investigation; Puyang City

\begin{abstract}
The purpose of this study is to understand the mental health status of teachers in primary and secondary schools, analyze the causes of the problems, and put forward some suggestions to solve the problems. This study mainly uses the questionnaire survey method, the use of the mental health self rating scale (SCL-90) and primary and secondary school teachers occupational stress condition survey questionnaire carries on the data and the data collection, the survey result uses the SPSS10.5 to carry on the data processing. The psychological obstacles of primary and secondary school teachers the detection rate of $45.44 \%$. among $30.09 \%$ teachers belonging to mild mental disorder, $12.63 \%$ of the teachers are moderate mental disorder, $2.72 \%$ teachers constituted mental illness .The overall condition of the psychological heal of primary and middle school teachers is obviously lower than the normal people's level. From the angle of the distribution characteristics, the proportion of the male teachers with psychological barriers is higher than the female teachers. In ten SCL-90 factors of psychological barriers, the most common symptoms of the primary and middle school teachers are compulsion, interpersonal relations disturbance, paranoia and melancholia.
\end{abstract}

\section{Research purpose}

The purpose of this study is to understand the mental health status of teachers in primary and secondary schools, analyze the causes of the problems, and put forward some suggestions to solve the problems.

\section{Research Design}

Research Objects Limited manpower, financial resources and time requirements, the survey only the scope of Puyang City. Sampling from Puyang City municipal, District Hualong, high tech Zone, Puyang County, Qingfeng County, Nanle County, Fanxian and Taiqian County 40 schools, Puyang City directly under the municipal government and the counties from each 5 schools as the research sample. Questionnaires were distributed to 1200 sets ,each consisting of $S C L-90$ and primary and secondary school teachers vocational stress status survey. Total questionnaires 1168 set, SCL-90 valid questionnaires in 1140, efficiency of 97.6\%; primary and secondary school teachers occupational stress status questionnaire valid questionnaires for 1150, efficiency was $98.5 \%$. 
Research Methods This study mainly uses the questionnaire survey method, the use of the mental health self rating scale (SCL-90) and primary and secondary school teachers occupational stress condition survey questionnaire carries on the data and the data collection, the survey result uses the SPSS 10.5 to carry on the data processing.

\section{Research Tool}

Mental health self rating scale (SCL-90) This study mainly uses mental health self rating scale (SCL-90) as an investigative tool, it is most widely used in the detection of mental health scale of, including 90 items, has a large capacity, reflecting spirit symptoms wide, easy to operate, and other characteristics, there is very important reference value.

\section{Primary and secondary school teachers occupational stress situation questionnaire}

Primary and secondary school teachers occupational stress status questionnaire is designed by Dr. Li Chaoping, from the Institute of public administration of Renmin University of China Institute of organizational and human resources Dr. Li Chaoping reference to the latest research results from the domestic and international occupational health psychology. This study is slightly modified.

Research Procedures In September 2015 to collect data, the preparation of the questionnaire and interview questions to determine the research object; A questionnaire survey was conducted in October 2015; In November 2015, a questionnaire was made and the results were processed and analyzed; In December 2015, the system of research materials, writing research reports.

\section{Results}

\section{Mental health status}

The general level of mental health of primary and middle school teachers is lower than that of normal adults. The psychological obstacles of primary and secondary school teachers the detection rate of $45.44 \%$. Among $30.09 \%$ teachers belonging to mild mental disorder, $12.63 \%$ of the teachers are moderate mental disorder, $2.72 \%$ teachers constituted mental illness. This result has far exceeded the normal population index (about 20\%).1999 years of primary and middle school students mental state health education research group in Liaoning Province, 2292 teachers were $S C L$ - 90 detection, that the psychological barriers of K-12 teachers' incidence of amazing data up to $51.23 \%$, when many were skeptical. The results of this study although the overall detection rate is lower than the Liaoning number, but the ratio of mental illness is much higher. That is worrying the mental health status of primary and middle school teachers.

The detection rate of mental disorder of male teachers is higher than that of female teachers The survey found that $47.99 \%$ male teachers were detected with mental disorders, which mild mass $31.92 \%$, moderate accounted for $13.17 \%$, severe accounted for $2.90 \%$; female teachers overall psychological obstacle detection rate of $43.79 \%$, which mild $28.90 \%$, moderate $12.28 \%$, severe accounting for $2.60 \%$ (refer with: Table 1). The SPSS11.5 software to test the significant difference found the level of mental health of male teachers were significantly lower than that of female 
teachers' and except somatization, forcing, depression and paranoia factor no significant differences, other factors have significant differences. Among them, two factors of anxiety and terror was extremely significant difference (refer with: Table 1).

Table 1 Comparison of detection results between male teachers and female teachers' SCL - 90 ( $\bar{X} \pm$ SD) $\quad($ Note: $* \mathrm{P}<0.05, * * \mathrm{P}<0.01)$

\begin{tabular}{|c|c|c|c|}
\hline factor & male $(\mathrm{n}=448)$ & female $(\mathrm{n}=692)$ & $\mathrm{t}$ \\
\hline Total average & $1.69 \pm 0.58$ & $1.62 \pm 0.53$ & $2.05^{*}$ \\
\hline somatization & $1.55 \pm 0.52$ & $1.56 \pm 0.53$ & -0.31 \\
\hline compulsion & $1.91 \pm 0.61$ & $1.85 \pm 0.56$ & 1.67 \\
\hline $\begin{array}{c}\text { interpersonal } \\
\text { relations } \\
\text { disturbance }\end{array}$ & $1.92 \pm 0.62$ & $1.82 \pm 0.53$ & $2.81^{* *}$ \\
\hline melancholia & $1.73 \pm 0.61$ & $1.71 \pm 0.60$ & 0.54 \\
\hline Anxiety & $1.63 \pm 0.52$ & $1.52 \pm 0.45$ & $3.68^{* *}$ \\
\hline hostility & $1.68 \pm 0.60$ & $1.57 \pm 0.55$ & $3.12^{* *}$ \\
\hline terror & $1.45 \pm 0.45$ & $1.35 \pm 0.40$ & $3.83^{* *}$ \\
\hline paranoia & $1.64 \pm 0.63$ & $1.62 \pm 0.60$ & 0.53 \\
\hline psychoticism & $1.42 \pm 0.43$ & $1.38 \pm 0.42$ & 1.54 \\
\hline
\end{tabular}

The detection rate of rural teachers' mental disorder is higher than that of urban teachers Rural teachers' Psychological Obstacles of total examination rate and light, medium and severe detection rate was $47.16 \%$ respectively and $30.85 \%, 13.30 \%$ and $3.01 \%$, and the corresponding figures for urban teachers were $43.75 \%$ and $29.34 \%, 11.98 \%$ and $2.43 \%$ (refer with: Table 2). The SPSS11.5 software to test the significant difference found their overall there was a significant difference, which forced and paranoid factor the difference was very significant, differences in factor of anxiety extremely significant ( refer with: Table 2), suggesting that in lower overall situation of primary and secondary school teachers' mental health level of rural teachers is particularly prominent.

Table 2 Comparison of detection results of SCL - 90 between rural teachers and urban teachers ( $\bar{X}$ $\pm \mathrm{SD}) \quad($ Note: $* \mathrm{P}<0.05, * * \mathrm{P}<0.01)$

\begin{tabular}{|c|c|c|c|}
\hline factor & $\begin{array}{c}\text { rural teachers } \\
(\mathrm{n}=564)\end{array}$ & $\begin{array}{c}\text { urban teachers } \\
(\mathrm{n}=576)\end{array}$ & $\mathrm{t}$ \\
\hline Total average & $1.68 \pm 0.53$ & $1.61 \pm 0.51$ & $2.27^{*}$ \\
\hline somatization & $1.57 \pm 0.49$ & $1.54 \pm 0.47$ & 1.05 \\
\hline compulsion & $1.92 \pm 0.60$ & $1.83 \pm 0.56$ & $2.61^{* *}$ \\
\hline $\begin{array}{c}\text { interpersonal } \\
\text { relations } \\
\text { disturbance }\end{array}$ & $1.90 \pm 0.62$ & $1.82 \pm 0.58$ & $2.24^{*}$ \\
\hline melancholia & $1.76 \pm 0.61$ & $1.60 \pm 0.56$ & $2.31^{*}$ \\
\hline
\end{tabular}




\begin{tabular}{|c|c|c|c|}
\hline Anxiety & $1.61 \pm 0.49$ & $1.51 \pm 0.44$ & $3.61^{* *}$ \\
\hline hostility & $1.64 \pm 0.59$ & $1.60 \pm 0.56$ & $1.17^{*}$ \\
\hline terror & $1.40 \pm 0.45$ & $1.38 \pm 0.44$ & 0.76 \\
\hline paranoia & $1.67 \pm 0.66$ & $1.57 \pm 0.59$ & $2.70^{* *}$ \\
\hline psychoticism & $1.41 \pm 0.44$ & $1.39 \pm 0.43$ & 0.78 \\
\hline
\end{tabular}

The outstanding performance of mental disorder symptoms in primary and middle school teachers In 10 psychological obstacle factor of SCL - 90 test, sorted according to the level of detection rate followed by forcing, interpersonal relationship, paranoia, depression, somatization, anxiety and other (sleeping and eating), hostile, terror and psychosis factor (refer with:Table 3). Survey found, $30.41 \%$ of the surveyed teachers forcing factors was positive in 10 factors first, followed by interpersonal relationship factor $(29.65 \%)$, paranoid ideation $(29.39 \%)$ and depression factor $(28.16 \%)$ above four factor symptoms were prominent, is the main problem that exist in primary and secondary school teachers' mental health.

Table 3 the distribution of SCL-90 positive factors in primary and middle school teachers $(n=1140)$

\begin{tabular}{|c|c|c|c|}
\hline factor & Positive cases & percentage & Precedence \\
\hline somatization & 286 & 25.09 & 5 \\
\hline compulsion & 349 & 30.41 & 1 \\
\hline interpersona & 338 & 29.65 & 2 \\
\hline melanchol & 321 & 28.16 & 4 \\
\hline Anxiety & 259 & 22.72 & 6 \\
\hline hostility & 201 & 17.63 & 8 \\
\hline terror & 163 & 14.30 & 9 \\
\hline paranoia & 335 & 29.39 & 3 \\
\hline psychotici & 126 & 11.05 & 10 \\
\hline other & 207 & 18.15 & 7 \\
\hline
\end{tabular}

\section{Occupational stress situation}

The overall situation of the professional pressure of teachers in primary and secondary schools is not optimistic. Relatively large occupational stress of teachers accounted for $69.5 \%$ overall survey, of which $29.6 \%$ of the teachers have high occupational stress and $39.9 \%$ of the teachers have great professional pressure, only 30.5 percent of teachers without or with slight occupational stress. This shows that small school teachers widespread heavy psychological pressure, and a serious impact on the mental health of their. Male teachers face higher occupational stress than female teachers. The occupational stress of rural teachers is higher than that of urban teachers. The occupational stress of junior middle school teachers is higher than that of primary and middle school teachers.

Stressors Survey results show that caused by the investigation of teachers occupational stress and psychological health problems the main reason has the following several aspects: the new 
curriculum reform put forward more high requirements; school management system existing problems; salary and reward (including the heavy economic burden and work can not be objective and impartial evaluation and reward); social environmental factors (including teachers social status is not high and the school, parents and society pay too much attention to students' scores) and family factors.

\section{Conclusions}

First, middle and elementary school teachers' psychological health is obviously lower than the normal population levels. Psychological obstacle detection rate as high as $45.44 \%$, which $30.09 \%$ teachers belongs to mild mental disorder, $12.63 \%$ of teachers belonging to moderate mental retardation, $2.72 \%$ of the teachers have a mental illness. The results have gone far beyond the normal population index (about 20\%).

Second, from the view of the distribution characteristics, male teachers' psychological obstacle detection rate was significantly higher than that of female teachers, $47.99 \%$ male teachers were detected in a psychological disorder, female teachers detection rate of 43.79\%; rural teachers' psychological obstacles detection rate was significantly higher than that of urban teachers, Rural Education Division of mental disorder check out rate was $47.16 \%$, and urban teachers was $43.75 \%$; junior middle school teachers' mental health problem is elementary and high school is the most prominent, three compared highest junior high, $49.42 \%$, high school was $46.59 \%$ detection rate of teachers' psychological obstacles, primary for $40.74 \%$ respectively.

Third, in SCL-90 of the 90 psychological barriers, the primary and secondary school teachers, the most prominent symptoms of positive symptoms are forced, interpersonal, paranoid and depressed four factors, respectively, $30.41 \%, 29.65 \%, 29.39 \%$ and $28.16 \%$.

Fourth, primary and secondary school teachers' mental health problems and they face great occupational stress is closely related. The survey found that relatively large occupational stress of teachers accounted for $69.5 \%$ overall survey, of which $29.6 \%$ of the teachers have high occupational stress and $39.9 \%$ of the teachers have great professional pressure, only 30.5 percent of teachers without or with slight occupational stress.

Fifth, primary and secondary school teachers occupational stress source of stress mainly is: the new curriculum reform put forward higher requirements (including passively adapt to the new curriculum reform, the teachers' professional ability of the increasingly high demand); school management system in the problems (including too many rigid examination and appraisal, heavy work load and unit relationships complex); salary and reward (including heavy economic burden and can't get an objective, impartial evaluation and return); social environmental factors (including the social status of teachers is not high and schools, parents and the society pay much attention to the students' scores) and family factors (children's education or employment problems).

Sixth, teachers in primary and secondary schools have a general lack of mental health knowledge, lack of scientific methods to deal with psychological stress, the school and the society have not paid enough attention to this issue. 
The end of this essay also analyses the cause of such problems and employs relevant countermeasure from the perspective of society, schools, families and teachers themselves. The first, the whole society in which all professions and trades should set up the "mass education" idea--education serve the whole society and it is necessary for the whole society to undertake responsibility. The second, the schools ought to construct "harmonious campus" actively, providing a sweet, harmonious working environment for the primary and middle school teachers. The third, the primary and middle school teachers should make great effort to construct happy and harmonious families. The fourth, teachers in primary and middle schools must pay attention to the development and excellence of the self mental quality, forming and possessing proficient mental quality.

\section{References}

[1] Pei Dina. Primary and secondary school teachers' Health Handbook [M]. Beijing: Chinese press, 1995

[2]Zhang Xiangluo. Teachers' psychological health education [M]. Beijing: Dolphin press, 2005

[3]Zhang Ling, et al. Research and guidance on mental health [M]. Beijing: Education Science Press, 2001. 